\title{
Maxillary Ameloblastoma, Epidemiological Aspects and Treatment at the Yalgado Ouedraogo University Hospital (Burkina Faso)
}

\author{
T. Konsem ${ }^{1 *}$, M. Millogo' ${ }^{1}$ R. W. L. Ouedraogo ${ }^{2}$, V. Ili1 ${ }^{1}$, L. Ouedraogo ${ }^{1}$, A. Coulibaly', D. Ouedraogo ${ }^{1}$ \\ ${ }^{1} \mathrm{HU}-\mathrm{YO}$, Ouagadougou, Burkina Faso \\ ${ }^{2} \mathrm{CHU}$-SS, Bobo-Dioulasso, Burkina Faso \\ Email: *tarcissus@hotmail.com
}

How to cite this paper: Konsem, T., Millogo, M., Ouedraogo, R.W.L., Ili, V., Ouedraogo, L., Coulibaly, A. and Ouedraogo, D. (2018) Maxillary Ameloblastoma, Epidemiological Aspects and Treatment at the Yalgado Ouedraogo University Hospital (Burkina Faso). Open Journal of Stomatology, 8, 149-157.

https://doi.org/10.4236/ojst.2018.85014

Received: February 27, 2018

Accepted: May 7, 2018

Published: May 10, 2018

Copyright $\odot 2018$ by authors and Scientific Research Publishing Inc. This work is licensed under the Creative Commons Attribution International License (CC BY 4.0).

http://creativecommons.org/licenses/by/4.0/

\begin{abstract}
Purpose: To report any epidemiological, anatomo-clinical and therapeutic aspects of maxillary ameloblastoma at the Yalgado Ouedraogo University Hospital (CHU-YO). Materials and Method: This was a descriptive and retrospective study covering the period ranging from January 1, 2010 to December 31, 2016. All patients received in the stomatology department for maxillary ameloblastoma with histological confirmation were included in the study. Consultation registers were used as the basis for data collection. Results: In our study, 50 cases were reported, i.e. an incidence of 7.14 cases per year. The mean age was 30.16 years with a sex ratio of 0.56 . Housewives were the most affected and the average time to consultation was 2.5 years. The site of the tumor was in the majority of cases the mandible $82 \%$, with swelling as the main reason for consultation. X-rays showed a predominance of monogeodic images in $56 \%$ of the cases. Conservative surgery was performed in $56 \%$ of the cases. Conclusion: Ameloblastoma is common in our area, characterized by delayed consultation. Strengthening of the technical facilities and awareness campaigns for the populations for early consultation are required.
\end{abstract}

\section{Keywords}

Ameloblastoma, Maxillary, Epidemiology, Treatment, Ouagadougou

\section{Introduction}

Ameloblastoma is a common benign and odontogenic tumor.

Maxillofacial tumors were ranked second in stomatological and maxillofacial among pathologies after trauma at CHU-YO. Ameloblastoma is characterized by its tendency to relapse. Its treatment is a real challenge for surgeons who have to 
treat the patient with a low recurrence risk while ensuring them an optimal aesthetic and functional result [1].

Due to the therapeutic difficulties encountered, this tumor is feared in our context.

In order to help improve the management of this tumor, our study describes the epidemiological aspects and the processes of its treatment in our context.

\section{Methodology}

We carried out a retrospective and descriptive study which covered a period of seven years, January 1, 2010 to December 31, at the University Hospital of Ouagadougou (CHU-YO), in the Department of Stomatology and Maxillofacial Surgery.

Our study population included all patients seen in this department during the defined period and who consulted in the department with an ameloblastoma diagnosis confirmed histologically. This was a historical cohort.

We collected data using a data collection sheet designed for this purpose and including the items of the parameters of our study. This data collection process used consultation records in the operating theater and those of the department of pathological anatomy and cytology.

The parameters of our study were epidemiological (age, sex,), clinical and paraclinical (reason for consultation, physical sign, topography of ameloblastoma type of radiographic image), and therapeutic (method of surgical and evolution).

Patients have previously consented to participate in the study.

\section{Results}

\section{Epidemiological Data}

\section{Frequency}

Over a 7-year period, we identified 50 histologically confirmed ameloblastoma cases managed in the stomatology and maxillofacial surgery department, i.e. an annual incidence of 7.14 cases.

\section{Age and Gender}

The average age of our patients was 30.16 years \pm 14.17 with extremes of 5 years and 65 years. The 20 - 30 years age group was the most affected with 15 cases or $30 \%$.

We registered 18 male patients (36\%) and 32 female patients (64\%). The sex ratio was 0.56 .

\section{Socio-professional groups}

In our study, the dominant socio-professional group was represented by housewives (17 cases or $34 \%$ ), followed by pupils and students (14 cases) and farmers ( 9 cases). Other socio-professional groups come last with 10 cases.

\section{Clinical and Paraclinical Data}

\section{Time taken before going to consultation}

The average time to consultation was 2.5 years, with extremes ranging from 1 
month to 20 years.

Table 1 provides the distribution of cases according to the time taken before consultation.

\section{Reason for consultation}

The majority of our patients attended hospital for swelling in $92 \%$ of the cases.

Tumor Location

Mandibular localization was the most common in 41 cases, i.e. 82\%, against 9 cases with maxillary localization (18\%).

\section{Physical signs of the tumor}

\section{Size of the swelling}

The average size of the major axis was $6.53 \mathrm{~cm}$ with extremes ranging from 2 to $10 \mathrm{~cm}$.

Tumor consistency was firm in $40 \%$ of the cases. Tumor consistency was distributed as follows (Table 2).

\section{Radiological aspect of the tumor}

We have recorded overall osteolytic images within the bone matrices. There was a monogeodic image in $56 \%$ of the cases and in the remaining $44 \%$ it was polygeodic.

In mandibular tumors cases, the cortex was preserved in 22 patients (53.66\%) while it was broken in the other 19 cases (46.34\%).

\section{Histological Examinations}

Histological examinations were performed on the surgical specimens in all patients.

Table 1. Distribution of patients according to consultation time.

\begin{tabular}{ccc}
\hline Time to consultation [years] & Number $(\mathrm{N}=50)$ & Percentage (\%) \\
\hline$<1$ & 17 & 34.00 \\
{$[1-3[$} & 21 & 42.00 \\
{$[3-5[$} & 3 & 6.00 \\
{$[5-10]$} & 8 & 16.00 \\
$>10$ & 1 & 2.00 \\
Total & 50 & 100.00
\end{tabular}

Table 2. Distribution of patients according to tumor consistency.

\begin{tabular}{ccc}
\hline Tumor Consistency & Number $(\mathrm{n}=50)$ & Percentage (\%) \\
\hline Bony & 8 & 16 \\
Firm & 20 & 40 \\
Firm and renitent in some parts & 19 & 38 \\
Bony and renitent in some parts & 2 & 4 \\
Soft & 1 & 2 \\
Total & 50 & 100 \\
\hline
\end{tabular}


Table 3. Distribution of histological types.

\begin{tabular}{ccc}
\hline Histological Types & Number & Percentage (\%) \\
\hline Follicular and cystic & 16 & 32 \\
Follicular & 14 & 28 \\
Plexiform & 12 & 24 \\
Fibrous and cystic & 6 & 12 \\
Fibrous and plexiform & 1 & 02 \\
Kerato ameloblastoma & 1 & 02 \\
Total & 50 & 100 \\
\hline
\end{tabular}

\section{Therapeutic Data}

\section{Anesthesia}

All patients received a preoperative check-up and pre-anesthesia consultation. General anesthesia was used in 47 patients, and 3 patients received local anesthesia.

Intubation was performed in 47 patients. It was nasotracheal in $85.10 \%$ of the patients, and orotracheal in $12.17 \%$ of the patients. We recorded one tracheotomy case (2\%).

\section{Surgical procedures}

The intra-oral approach was first used in 35 patients (70\%) while in the other 15 patients we used both the extra-oral and intra-oral routes.

The most practiced exeresis was enucleation which was performed in $56 \%$ of the cases.

Of the cases of interruptive resection, 9 underwent reconstruction, including 8 cases per splint and 1 case per fibular transplant.

\section{Post-therapeutic evolution}

We recorded 3 cases of superinfection. Sequelae were labial and chin anesthesia in 5 cases and facial asymmetry in 3 cases after a 3-year follow-up. No recurrence was recorded within this time period.

\section{COMMENTS}

\section{Epidemiological Aspects}

We observed an annual incidence of 7.14 cases.

This incidence is higher than that reported by Crezoit GE. et al. [2] in Côte d'Ivoire who reported 3 cases per year.

Higher incidences have been reported by Olaitan A A. et al. [3] in Nigeria and Ruhin B. et al. [4] in France, who had found 16 cases of incidence per year and 18.38 cases per year respectively.

The frequency of this tumor is high and varies depending on the series.

The mean age of the patients in our series was 30.16 years old. The $20-30$ age group was the most represented with 15 patients.

Our results may be explained by the young structure of the population of our country. Other authors have found results that are similar to ours. Sophia N [5] 
reported in their series, a mean age of 30 years.

In our study series, the ages of our patients ranged from 5 years to 65 years. These results confirm that, although ameloblastoma is a tumor which affects young adults in particular, it can affect people of all ages.

In our study, we observed a clear female predominance in $64 \%$ of our cases. This could be explained by the fact that the female population is more attached to physical care than men. Sophia N. et al. [5] found equality between men and women [5], whereas Hassine [6] found a male predominance.

We could conclude that gender predominance varies depending on the series.

In our study, the most represented socio-professional group was housewives with $35.42 \%$. Our results could be explained by the relative predominance of housewives in the general female population.

\section{Clinical and paraclinical aspects}

Ameloblastoma is a slow-growing and painless tumor. This explains the long time taken before going to consultation, which causes tumors to be of very large volume.

The classical, firm and renitent consistency in some parts is often modified by the long evolution of these tumors in our context where traditional practices such as scarifications expose the patient to fistulizations and superinfections.

In our study, the vast majority, i.e. $82 \%$ of the cases were mandibular (Figure 1 and Figure 2).

Similar findings have been reported by other studies such as Sophia et al. [5] (88.4\%). Indeed, mandibular localizations are predominant as confirmed by

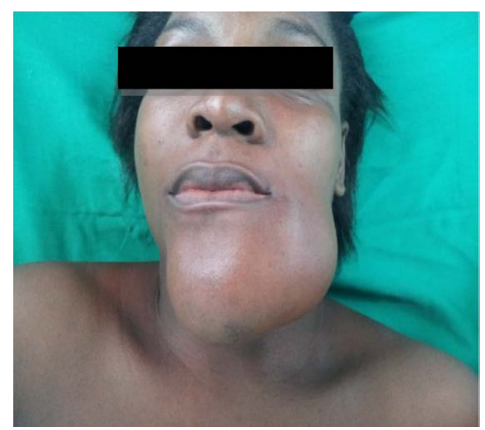

Figure 1. Mandible ameloblastoma (Young woman 32 Years).

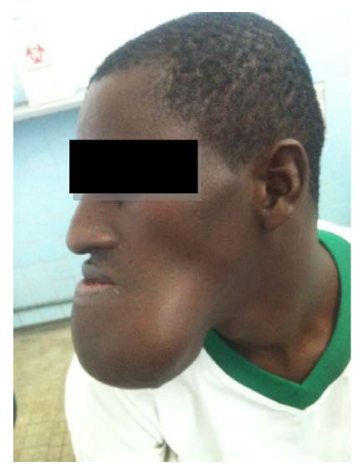

Figure 2. Mandible ameloblastoma (Young man 28 years). 


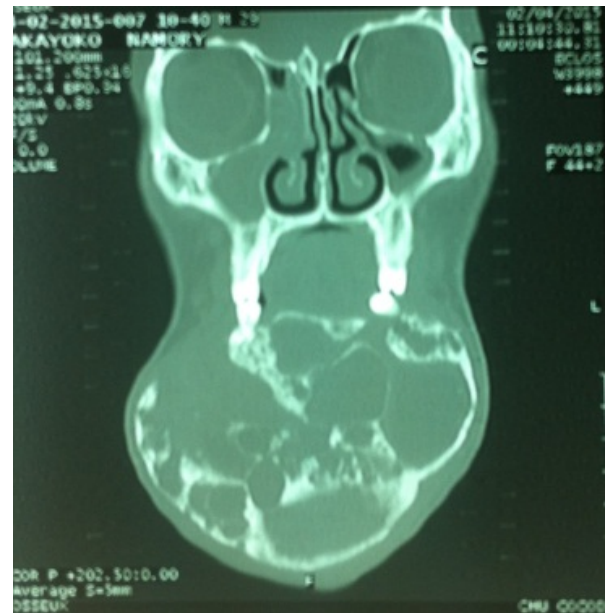

Figure 3. Radiological image of the mandible ameloblastoma in the young woman 32 years in Figure 1.

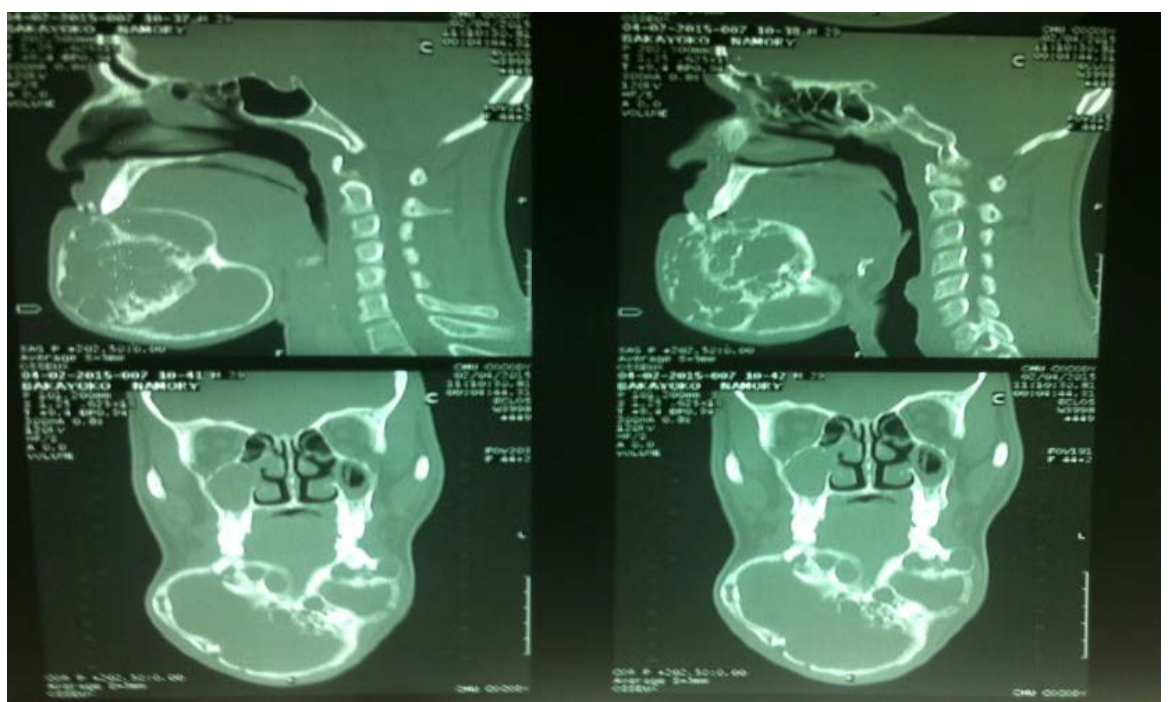

Figure 4. Radiological image (young man 28 years in Figure 3).

many authors.

Imaging plays a key role in presumptive diagnosis [7].

The most recurrent radiological image in our study was monogeodic in $56 \%$ of the cases and polygeodic in 44\% of the cases (Figure 3 and Figure 4).

In our series, there were $53.66 \%$ of mandibular ameloblastoma with a preserved cortex against $46.34 \%$ with fractured cortex. The condition of the mandibular cortex was assessed through radiography and often during surgery.

It is an important parameter in the choice of the type of exeresis. Indeed, when the cortex is broken, radical surgery is required.

All examinations were performed on surgical specimens.

The anatomical and pathological study of the surgical specimens of our study revealed a predominance of folliculo-cystic ameloblastoma (Table 3) in 16 cases (32\%), followed by the follicular type represented by 14 cases $(28 \%)$.

The series of Hassine et al. [6] showed a predominance of the follicular sub- 
type.

\section{Therapeutic Aspects}

All patients in our series received surgical treatment under general or local anesthesia.

General anesthesia was used in 47 patients, i.e. $94 \%$ of our patients. In our series, 3 patients benefited from a local and regional anesthesia.

The cases of general anesthesia concerned all patients operated in the operating room as part of the department's programs for large volume tumors with the major axis measuring more than $3 \mathrm{~cm}$. Local and regional anesthesia involved cases of in-chair enucleation, for tumors discovered early enough with major axis measuring less than $3 \mathrm{~cm}$.

The duration of the interventions and the mutilating nature of the surgery of large tumors require general anesthesia.

Nasotracheal intubation was performed in $85.10 \%$ of the patients while orotracheal intubation was used in $12.17 \%$ of them. This finding could be explained by the fact that nasotracheal intubation offers more comfort to the surgeon for an intervention in the oral cavity [5].

The intraoral route was used in all our patients. It was exclusive in $70 \%$ and supplemented by the extraoral route in $30 \%$ of the cases. This finding could be explained by the fact that the intraoral route limits surgical scars. As long as this route is possible, it is preferred to the cutaneous one.

For Ruhin B. et al. [8], preventive treatment of benign tumors and cysts of the mandible should be done using a mucosal approach. Only small tumors in the symphyseal region can be resected through the intra-oral route, provided that the surgeon is certain in any place that they will not perform a break-in that is likely to expand the tumor in the soft tissues [9] [10].

In our study, the practice of enucleation was slightly more common than that of interruptive resection in $56 \%$ of the cases.

The choice between radical surgery and conservative surgery remains a major concern for maxillofacial surgeons.

Conservative treatment provides the patient with a better socio-professional reintegration opportunity because the sequelae of the surgery are minimal. It is a stand-by treatment waiting for histological certainty due to the difficulty of making a diagnosis which clearly distinguishes ameloblastoma from other mandibular cysts (follicular cyst and epidermoid cyst). But it requires a more rigorous patients' follow-up to detect possible recurrences and to treat them.

Bataille et al. consider that if the indication of the conservative method is well posed and if the surgery is well conducted, conservative treatment will still keep its place, even if it is no longer the first approach in the treatment of ameloblastoma [11].

Reconstruction of bone loss in the mandible remains an actual challenge for maxillofacial surgeons, as the goal is no longer to obtain a simple continuity, but to restore aesthetics and function [8] [10] [12]. In our study, we identified 9 cases of reconstruction, including one definitive reconstruction (fibular graft) and 8 
cases of stand-by treatment. Indeed, splints have to be removed 6 months later for autologous transplant reconstruction (fibula, rib) in our context. In countries where technical facilities are well developed, fibula flap, or the Chinese flap plays a key role.

\section{Evolution}

In postoperative follow-up, we recorded in the medium term, 6 cases of labial and chin anesthesia, 4 cases of suppuration, and 1 case of material exposure after immediate splint reconstruction.

Cases of suppuration could be attributed to non-observance of oral hygiene and non-compliance with medication by patients. Cases of labial and chin anesthesia are caused by damage to the alveolar nerve that can be injured during the surgery or even taken away when it is involved in a fibrous reconstruction of the tumor, especially if this tumor has been the subject of scarifications in traditional treatments.

Sequelae are generally aesthetic and functional.

In our study, we observed a predominance of functional sequelae. These sequelae are often due to radical surgery, but also to cases of enucleation when the nerve is caught in a fibrous gangue of large volume tumors.

\section{Conclusion}

Maxillary ameloblastoma is a common benign tumor in Burkina Faso. It mostly affects young adults with a predominance of women in our series. Its clinical evolution is slow and silent. Time taken before attending health center for consultation is longer in our context. Its diagnosis is suspected by the clinical examination and the $\mathrm{X}$-ray but its confirmation remains histological based on surgical specimens. Radical surgery with free flap reconstruction is the first-line treatment. But in our context, there is a lack of appropriate technical facilities. Therefore, it is necessary to set up high-performance technical facilities, to train even more maxillofacial surgeons in order to improve the management of this pathology.

\section{Conflict of Interest}

All the authors declare: We have no conflict of interest.

\section{References}

[1] Dostie, A., Frechette, J.P. and Chehade, A.J. (2008) A Review of Odontogenic Tumors. Journal de lordre des dentistes du Québec, 45, 16-19.

[2] Crezoit, G.E., Gadegbeku, S., Ouattara, B. and Bile, J. (2003) Maxillary Ameloblastoma. Revue de stomatologie et de chirurgie maxillo-faciale, 104, 25-28.

[3] Olaitan, A.A. and Adekeye, E.O. (1996) Clinical Features and Management of Ameloblastoma of the Mandible in Children and Adolescents. British Journal of Oral and Maxillofacial Surgery, 34, 248-251. https://doi.org/10.1016/S0266-4356(96)90279-X

[4] Ruhin-Poncet, B., Bouattour, A., Picard, A., Menard, P., Capron, F. and Bertrand, 
J.-C. (2011) Ameloblastoma of the Jaws: A Retrospective Analysis from 1994 to 2007. Rev Stomatol Chir Maxillofac, 112, 269-279.

https://doi.org/10.1016/j.stomax.2011.05.004

[5] Sophia, N., Malik, B., Imane, T., Laila, E. and Mohammed, K. (2009) Ameloblastoma: Diagnosis and Treatment. Report of 26 Cases. Médecine buccale chirurgie buccale, 15, 93-100.

[6] Hassine, M.B.H., Oualha, L., Ayachi, S., Kalaï, S., Khochtali, H. and Douki, N. (2017) Ameloblastoma: A Retrospective Study. Actualités Odonto-Stomatologiques, No. 284, 1-5.

[7] N'dri, K., Konate, I., Bravo-Tsri, B., et al. (2013) Radiological Aspects of Mandibular Ameloblastoma: Report of 23 Cases. Journal Afr imag Méd, 3, 143-147.

[8] Ruhin, B., Guilbert, F. and Bertrand, J.C. (2005) Treatment of Benign Maxillary Cysts, Tumors and Pseudotumors. EMC Stomatologie. Elsevier SAS, Paris, 22-062-K-10. 49.

[9] Kitagawa, Y., Baur, D., King, S. and Helman, J.I. (2003) The Role of Midfacial Degloving Approach for Maxillary Cysts and Tumors. Journal of Oral and Maxillofacial Surgery, 61, 1418-1422. https://doi.org/10.1016/j.joms.2002.09.001

[10] Reychler, H. (1988) Bone Tumors of the Maxillae. Revue de stomatologie et de chirurgie maxillo-faciale, 89, 330-338.

[11] Bataille, R., Schumann, C.L. and Seghir, M. (1974) A Report of Several Cases of Primitive or Recidivated Mandibular Ameloblastoma Treated by Surgical Curettage. Revue de stomatologie et de chirurgie maxillo-faciale, 75, 33-36.

[12] Ghandhi, D., Ayoub, A.F., Pogrel, M.A., Macdonald, G., Brocklebank, L.M. and Moos, K.F. (2006) Ameloblastoma: A Surgeon's Dilemma. Journal of Oral and Maxillofacial Surgery, 64, 1010-1014. https://doi.org/10.1016/j.joms.2006.03.022 